\title{
Functional impairment related to painful physical symptoms in patients with generalized anxiety disorder with or without comorbid major depressive disorder: post hoc analysis of a cross- sectional study
}

\author{
Irene Romera ${ }^{1 *}$, Ángel L Montejo ${ }^{2}$, Fernando Caballero ${ }^{3}$, Luis Caballero ${ }^{4}$, José Arbesú ${ }^{5}$, Pepa Polavieja ${ }^{1}$,
}

Durisala Desaiah ${ }^{6}$ and Inmaculada Gilaberte

\begin{abstract}
Background: Generalized anxiety disorder (GAD) is the most frequent anxiety disorder in primary care patients. It is known that painful physical symptoms (PPS) are associated with GAD, regardless the presence of comorbid major depressive disorder (MDD). However the specific role of such symptoms in patients' functional impairment is not well understood. The objective of the present study is to assess functional impairment related to the presence of PPS in patients with GAD.

Methods: This is a post hoc analysis of a cross-sectional study. Functioning, in the presence (overall pain score >30; Visual Analog Scale) or absence of PPS, was assessed using the Sheehan Disability Scale (SDS) in three groups of patients; 1) GAD and comorbid MDD (GAD+MDD+), 2) GAD without comorbid MDD (GAD+MDD-), 3) controls (GAD-MDD-). ANCOVA models were used.

Results: Of those patients with GAD+MDD+ ( $n=559), 436$ (78.0\%) had PPS, compared with GAD+MDD- (249 of 422 , $59 \%$ ) and controls (95 of 336, 28.3\%). Functioning worsened in both GAD groups in presence of PPS (SDS least squares mean total score: 16.1 vs. 9.8, $\mathrm{p}<0.0001, \mathrm{GAD}+\mathrm{MDD}+; 14.3$ vs. 8.2, $\mathrm{p}<0.0001, \mathrm{GAD}+\mathrm{MDD}-)$. The presence of PPS was significantly associated with less productivity.
\end{abstract}

Conclusions: Functional impairment related to the presence of PPS was relevant. Clinical implications should be considered.

\section{Background}

Generalized anxiety disorder (GAD), a mental disorder highly prevalent in primary care patients $(8 \%-14 \%)$, is generally associated with a significant impairment in patients' functioning [1,2]. Patients with GAD experience functional impairments, such as diminished social relationships, poorer well-being, and less satisfaction with life [3], that lead to reduced quality of life in the areas of interaction with friends, self-realization, subjective well-

\footnotetext{
* Correspondence: romera_irene@lilly.com

'Clinical Research Department, Lilly, SA, Avenida de la Industria, 30, 28108 Alcobendas, Spain

Full list of author information is available at the end of the article
}

being $[4,5]$, and work [6]. These patients are more likely to have absences from work and short-term disabilities; therefore, the indirect costs of the disease attributable to low productivity are increased [7]. The level of impairment is substantial and is even comparable to that of major depression [8]. As expected, the highest level of functional impairment occurs when GAD is comorbid with depression, which is a common feature in primary care $[1,8]$.

The pathological feature most uniquely associated with GAD and that differentiates it from other anxiety disorders is excessive, pervasive, and uncontrollable worrying [9-12]. Such worrying in patients with GAD is frequently

\section{C) Biomed Central}


accompanied by a host of psychiatric symptoms, including irritability, restlessness, and concentration difficulties. Patients also experience a range of somatic symptoms such as cold clammy hands, dry mouth, sweating, nausea, and diarrhea [13]. Additionally, patients with GAD often complain about muscle pain and aches [14]. One recent study found that painful physical symptoms (PPS) in primary care patients with GAD were twice as prevalent as in a control group and the presence of comorbid major depressive disorder (MDD) further increased their prevalence [8]. Another recent study [15] using a community sample $(\mathrm{N}=4181)$ showed a stronger association between GAD and pain (odds ratio, OR = 5.8 pain symptoms; $\mathrm{OR}=16.0$ pain disorder) compared to other anxiety disorders $(\mathrm{OR}=2.4$ pain symptoms; $\mathrm{OR}=4.0$ pain disorder).

Understanding the relationship between PPS and functional impairment in GAD could help clinicians to effectively manage these patients' treatment. Taking into account the poor treatment outcomes for GAD in terms of remission [16], it is clear that improved management of the disease is even more important. However, only a limited number of studies have focused on the specific role of PPS in functional and quality of life impairment in "real life" primary care patients, out of a clinical trial setting. As reported in a recent review, much of the research to date has focused on the prevalence of anxiety disorders in samples of patients that report chronic pain [17]. A small number of studies have assessed pain in patients with anxiety disorders, but most of them were limited to panic disorder and posttraumatic stress disorder and focused on chronic pain rather than PPS [18].

Our hypothesis is that the presence of PPS is associated with relevant and substantial functional- and healthrelated quality of life impairment in primary care patients with GAD, regardless of the presence of comorbid MDD. Previous studies have shown a significant deleterious effect of PPS on quality of life and functioning in patients with depression [19-22]. Therefore, the present study evaluates functional impairment associated with PPS patients with GAD, with or without MDD, in a primary care setting.

\section{Methods}

\section{Study design}

This is a post hoc analysis of a cross-sectional, multicenter epidemiological study that evaluated the prevalence of PPS in GAD patients with or without MDD [8]. Briefly, the study was carried out in a primary care setting covering 87 sites in Spain during April-June, 2007. The study had 3 stages in its design, including a consecutive screening to identify high-risk patients for GAD, a diagnosis confirmation of GAD along with an evaluation of the presence or absence of comorbid MDD, and a clinical evaluation for the presence of PPS (Figure 1).

\section{Eligibility criteria and study procedure Consecutive screening stage}

Patients $\geq 18$ years of age who presented at primary care centres for any reason were consecutively screened for GAD using the Hospital Anxiety and Depression ScaleAnxiety subscale (HADS-A) [23]. Patients with a score of $\geq 8$ were defined as positive and those with a score of $<8$ were defined as negative for GAD and consecutively selected as controls.

\section{Diagnosis confirmation stage}

Subsequent confirmation of the GAD diagnosis and evaluation for the presence or absence of comorbid MDD was administered per Diagnostic and Statistical Manual of Mental Disorders-Fourth Edition (DSM-IV) criteria by means of the Mini International Neuropsychiatric Interview (MINI) [13,24]. Controls, consecutively selected in the previous stage, were confirmed by a Hospital Anxiety and Depression Scale (HADS) total score of $<11$.

\section{Clinical evaluation for the presence of PPS stage}

After the first and second stages, three groups of patients were identified: 1) patients with GAD and comorbid MDD (GAD+MDD+); 2) patients with GAD without comorbid MDD (GAD+MDD-); and 3) controls (GADMDD-). Afterwards, the presence of PPS was clinically evaluated in these three groups of patients, who were classified as having or not having PPS $\left(\mathrm{PPS}^{+}\right.$and PPS ${ }^{-}$, respectively). Ultimately, six groups of patients were categorized, combining diagnoses and presence of pain (Figure 1).

\section{Exclusion criteria}

Patients demonstrating any condition that would impede their understanding of the study were excluded.

\section{Ethical and informed consent}

Prior to the collection of data, all patients were informed about the purpose and objectives of the study and voluntarily provided written informed consent. The local ethical review board of the Hospital de Salamanca provided approval of the study protocol (F1J-XM-B024) as being in compliance with the Helsinki Declaration.

\section{Patient assessment}

PPS were assessed by the Visual Analog Scale (VAS) for pain, which consists of six questions including overall pain, headache, back pain, shoulder pain, pain interference with daily activities, and time experiencing pain while awake [25]. The VAS overall pain severity score of $>30$ considered as the cutoff point in the identification of clinically significant PPS in patients with GAD [26], was adopted for identifying the presence of PPS $\left(\mathrm{PPS}^{+}\right)$. 


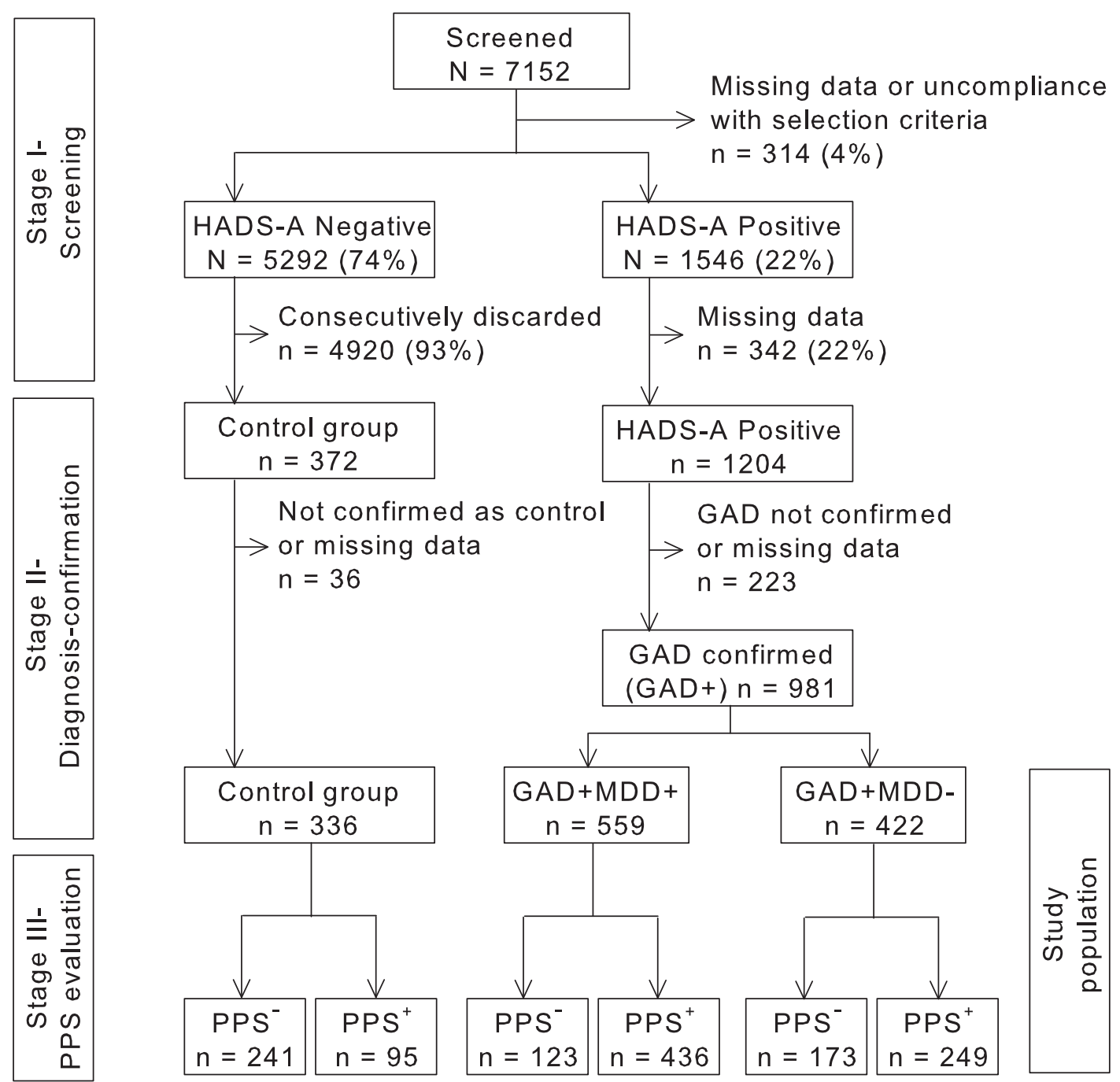

Figure 1 Patient disposition. Abbreviations: HADS-A = Hospital Anxiety and Depression Scale-Anxiety subscale; GAD = Generalized anxiety disorder; MDD = Major depressive disorder; PPS = Painful physical symptoms.

The Sheehan Disability Scale (SDS) was completed by the patient and used to assess functional status [27]. Using the SDS, 3 areas of the patient's life were scored: work, social life, and family life/home responsibilities. Response categories for each of these 3 areas had a score range from 0 to 10 . A higher score corresponds to a greater degree of disruption and impairment in each area of life, with a maximum score of 30 . In addition, the SDS includes questions about the number of lost days and the number of unproductive days during the prior week.

The EuroQoL-5D (EQ-5D), a standardized instrument [28] that measures health outcomes, was used to assess quality of life. It provides a simple descriptive profile and single index values for health status. The EQ-5D has 5 domains: mobility, self-care, usual activities, pain/ discomfort, and anxiety/depression. Scoring is on a 3point scale, with self-completed response records obtained from individual patients. Lower scores indicate poorer health status.

The Clinical Global Impression of Severity (CGI-S) scale [29] was used to assess the severity of the patient's symptoms. The CGI-S scale is a single-item rating of the clinician's assessment of the patient's symptoms severity. The severity score ranges from 1 (normal, not at all ill) to 7 (among the most extremely ill patients).

Other assessments (age, gender, education level, work status, current medical and psychiatric co-morbidities and existing treatments) were based on direct questioning to the patient and patient's clinical history. Checklists with the common co-morbidities were provided to the investigators. 


\section{Statistical analysis}

Sample size was estimated for the primary objective of the study, which was to assess the prevalence of PPS in GAD patients (GAD+MDD-) as compared to GAD patients with comorbid MDD (GAD+MDD+) and controls (GAD-MDD-) [8]. Therefore, it was estimated in order to achieve a power of $88 \%$ when comparing differences between a proportion of patients with PPS in the GAD+MDD-group of 44\% [30] and a proportion of patients with PPS in the control group of $30 \%$ [31]. On the other hand, the study would have a $80 \%$ power to detect the difference between a proportion of patients with PPS of $44 \%$ in the GAD+MDD- group and a proportion of patients with PPS of $57 \%$ in the GAD+MDD+ group [32] with the following sample sizes: 374 in the GAD+MDD- group, 249 in the GAD+MDD+ group, and 249 in the control group.

In previous studies [1], the prevalence of comorbid MDD in patients with GAD was approximately $40 \%$ and the prevalence of GAD in primary care patients was around $8 \%$. In order to obtain a final sample size of 249 patients in the comorbid group (GAD+MDD+), screening of 8650 patients was performed in order to adjust for a $10 \%$ rate of refusal to participate among patients who were invited to be screened.

Comparisons between patient groups regarding demographics, clinical characteristics, and current medications were made by means of a chi-square test for qualitative variables and by analysis of variance (ANOVA) for quantitative variables.

The associations between the presence of PPS and functioning in the different groups of diagnoses (GAD +MDD+; GAD+MDD-; control) were analyzed using an analysis of covariance (ANCOVA) model with the independent fixed effects combination of diagnosis and pain (categorized at six levels: the three different diagnoses combined with having pain or not), gender, age, medical, psychiatric comorbidities, and the CGI-S, interactions were not included. The dependent variable was the SDS total score. If the main effects were significant, pair wise comparisons between all categories in that particular effect were performed.

In order to evaluate the association between the presence of PPS and the number of underproductive days in the three different groups of diagnoses, a second ANCOVA model was developed including the same terms as well as the interaction age and diagnosis. The dependent variable was the number of underproductive days in the prior week, as measured by the SDS.

Finally, to evaluate the association between the presence of PPS and health status in the three different groups of diagnoses, a third ANCOVA model was developed including the same terms, with the dependent variable being the EQ-5D score. UK population norms were used for standardizing the EQ-5D score.

All statistical analyses were performed using SAS software (version 8.2).

\section{Results}

\section{Patient disposition}

Of the total 7152 screened patients, 1546 (22\%) tested positive for GAD and subsequently 981 (13.7\%) were confirmed as having a diagnosis of GAD. Of those patients, 559 (57\%) had GAD with comorbid MDD $(\mathrm{GAD}+\mathrm{MDD}+)$ and a large percentage of them had PPS $(78 \%, \mathrm{n}=436)$. Of the $422(43 \%)$ patients with GAD but without comorbid MDD (GAD+MDD-), 249 (59\%) had PPS. Of the remaining 5292 patients who screened negative, 336 were selected and confirmed as controls and 95 (28\%) of them had PPS (Figure 1).

\section{Patients demographics and clinical characteristics}

The mean (standard deviation: SD) age (years) was 52.2 (14.7) for GAD+MDD+ patients, 49.8 (14.5) for GAD +MDD- patients, and 50.8 (17.3) for control patients (Table 1). Patients with PPS were slightly older than those without PPS (ANOVA p-value $\leq 0.05, \mathrm{PPS}^{+}$vs. PPS ${ }^{-}$, for all groups: GAD+MDD+, GAD+MDD-, and control patients). Medical and psychiatric comorbidities were more prevalent in the presence of PPS in all the three different groups of diagnoses, but particularly in patients with GAD and comorbid MDD.

\section{Concomitant medications}

Regarding the use of psychotropic medication, 35.1\% of $\mathrm{GAD}+\mathrm{MDD}+$ patients and $17.5 \%$ of GAD+MDD- patients were using some type of antidepressant drug, with no significant differences between $\mathrm{PPS}^{+}$and $\mathrm{PPS}^{-}$patients. However, a more frequent use of benzodiazepines was reported particularly in $\mathrm{PPS}^{+}$patients (for GAD+MDD+ patients: $47.0 \%$ vs. $34.1 \%, \mathrm{p}=0.0111, \mathrm{PPS}^{+}$vs. $\mathrm{PPS}^{-}$respectively; for GAD+MDD- patients: $41.0 \%$ vs. $26.6 \%, \mathrm{p}=0.0023, \mathrm{PPS}^{+}$ vs. PPS $^{-}$, respectively). As expected, a significantly higher number of patients with GAD and PPS were taking analgesic or anti-inflammatory agents $(69.0 \%$ and $65.1 \%$ for GAD+MDD+ and GAD+MDD-, respectively), compared to those without PPS (35.8\% and 30.6\%, respectively; $\mathrm{p}<0.0001$ for both comparisons).

\section{Functional impairment related to the presence of PPS}

Patients with PPS in all groups exhibited significantly worse functional impairment compared to patients without PPS, as expressed by a significantly higher SDS total score $(\mathrm{F}$-value $=52.8$ for the combination of diagnoses and pain; $\mathrm{p}<0.0001, \mathrm{PPS}^{+}$vs. $\mathrm{PPS}^{-}$for $\mathrm{GAD}+\mathrm{MDD}+$, GAD+MDD-, and control groups). This result indicates 


\begin{tabular}{|c|c|c|c|c|c|c|}
\hline & \multicolumn{2}{|c|}{$\begin{array}{c}\text { GAD+MDD+ } \\
(\mathrm{N}=559)\end{array}$} & \multicolumn{2}{|c|}{$\begin{array}{l}\text { GAD+MDD- } \\
(\mathrm{N}=422)\end{array}$} & \multicolumn{2}{|c|}{$\begin{array}{c}\text { Control } \\
(\mathrm{N}=336)\end{array}$} \\
\hline & $\begin{array}{c}\text { PPS }^{+} \\
(N=436)\end{array}$ & $\begin{array}{c}\text { PPS }^{-} \\
(N=123)\end{array}$ & $\begin{array}{c}\text { PPS }^{+} \\
(N=249)\end{array}$ & $\begin{array}{c}\text { PPS }^{-} \\
(\mathrm{N}=173)\end{array}$ & $\begin{array}{c}\text { PPS }^{+} \\
(\mathrm{N}=95)\end{array}$ & $\begin{array}{c}\text { PPS }^{-} \\
(\mathrm{N}=241)\end{array}$ \\
\hline Gender, female, n (\%)* & $338(77.5)$ & $95(77.2)$ & $196(78.7)^{\mathrm{b}}$ & $118(68.2)$ & $64(67.4)^{c}$ & $119(49.4)$ \\
\hline Age (years), mean $(\mathrm{SD})^{* *}$ & $53.3(14.7)^{d}$ & $48.3(13.8)$ & $51.5(14.7)^{d}$ & $47.4(13.8)$ & $54.4(17.4)^{d}$ & $49.4(17.1)$ \\
\hline \multicolumn{7}{|l|}{ Medical comorbidities, n (\%) } \\
\hline At least one* & $329(75.5)^{\mathrm{a}}$ & $59(48.0)$ & $187(75.1)^{\mathrm{b}}$ & $81(46.8)$ & $66(69.5)^{c}$ & $122(50.6)$ \\
\hline Hypertension $^{\dagger}$ & $156(35.8)^{\mathrm{a}}$ & $29(23.6)$ & $76(30.5)$ & $38(22.0)$ & $28(29.5)$ & $72(29.9)$ \\
\hline Diabetes mellitus ${ }^{t+}$ & $56(12.8)^{\mathrm{a}}$ & $6(4.9)$ & $28(11.2)$ & $12(6.9)$ & $7(7.4)$ & $18(7.5)$ \\
\hline Coronary artery disease $^{\ddagger}$ & $29(6.7)$ & $4(3.3)$ & $8(3.2)$ & $3(1.7)$ & $4(4.2)$ & $8(3.3)$ \\
\hline Degenerative osteoarthritis* & $116(26.6)^{\mathrm{a}}$ & $10(8.1)$ & $61(24.5)^{b}$ & $21(12.1)$ & $29(30.5)^{c}$ & $25(10.4)$ \\
\hline \multicolumn{7}{|l|}{ Psychiatric comorbidities, n (\%) } \\
\hline At least one* & $146(33.5)^{\mathrm{a}}$ & $28(22.8)$ & $62(24.9)$ & $30(17.3)$ & $4(4.2)$ & $3(1.2)$ \\
\hline CGI-Severity, mean $(\mathrm{SD})^{* *}$ & $4.5(0.9)^{d}$ & $3.8(1.0)$ & $3.6(1.0)^{d}$ & $2.9(1.1)$ & $2.0(1.2)^{d}$ & $1.3(0.7)$ \\
\hline \multicolumn{7}{|l|}{ Current medication, n (\%) } \\
\hline Antidepressants* & $153(35.1)$ & $43(35.0)$ & $44(17.7)$ & $30(17.3)$ & $2(2.1)$ & $4(1.7)$ \\
\hline Benzodiazepines* & $205(47.0)^{\mathrm{a}}$ & $42(34.1)$ & $102(41.0)^{b}$ & 46 (26.6) & $8(8.4)$ & $10(4.1)$ \\
\hline Analgesics* & $265(60.8)^{a}$ & $36(29.3)$ & $140(56.2)^{b}$ & $36(20.8)$ & $55(57.9)^{c}$ & $38(15.8)$ \\
\hline NSAIDs* & $168(38.5)^{a}$ & $21(17.1)$ & $96(38.6)^{b}$ & $32(18.5)$ & $37(38.9)^{c}$ & $18(7.5)$ \\
\hline Analgesic/NSAIDs* & $301(69.0)^{\mathrm{a}}$ & $44(35.8)$ & $162(65.1)^{\mathrm{b}}$ & 53(30.6) & $66(69.5)^{c}$ & $46(19.1)$ \\
\hline
\end{tabular}

$\mathrm{GAD}=$ Generalized anxiety disorder; MDD = Major depressive disorder; PPS = Painful physical symptoms; SD = Standard deviation; CGI = Clinical Global Impression; NSAIDs = Non-steroidal anti-inflammatory drugs; ANOVA = Analysis of variance; ${ }^{*}$ Chi-square test $p \leq 0.0001 ;{ }^{* *}$ ANOVA $p \leq 0.0001$; +Chi-square test $p$ $=0.0123$; ††Chi-square test $p=0.0298$; $\neq$ Chi-square test $p=0.0662 ;{ }^{a}$ Chi-square $p \leq 0.05$ vs. GAD+MDD+ PPS patients; ${ }^{b}$ Chi-square $p \leq 0.05$ vs. GAD+MDD-PPS patients; ${ }^{\mathrm{C} C h i}$-square $\mathrm{p} \leq 0.05$ vs. controls PPS ${ }^{-}$patients; ${ }^{\mathrm{d}}$ ANOVA $\mathrm{p} \leq 0.05$ vs. PPS $^{-}$patients.

that the presence of PPS contributes to worse functional impairment in work, social, and family life, when adjusted by patients' severity (CGI-S scale), age, gender, or comorbidity, (Figure 2). As expected, functional impairment was worst in patients suffering from GAD and comorbid MDD and PPS (SDS total score least squares means [LSM] $[\mathrm{SD}]=16.1[0.5] \mathrm{p}<0.0001$ vs. GAD+MDD- and vs. control groups, regardless of the presence of PPS). Interestingly, the magnitude of the functioning impairment related to the presence of PPS was relevant as it was $>1.5$ fold worse when PPS was present (SDS total score LSM $[\mathrm{SD}]$ in $\mathrm{GAD}+\mathrm{MDD}+$ patients $=16.1[0.5]$ vs. $9.8[0.6] ; \mathrm{p}<$ $0.0001, \mathrm{PPS}^{+}$vs. PPS ; SDS total score LSM [SD] in GAD + MDD- patients $=14.3$ [0.5] vs. 8.2 [0.6]; $\mathrm{p}<0.0001, \mathrm{PPS}^{+}$ vs. PPS $^{-}$; SDS total score LSM [SD] in controls $=12.1$ [0.8] vs. 7.7 [0.7]; $\mathrm{p}<0.0001, \mathrm{PPS}^{+}$vs. $\mathrm{PPS}^{-}$). Other factors that significantly contributed to patients' functional impairment were: age $(\mathrm{F}$-value $=21.9 ; \mathrm{p}<0.0001)$, being female $(\mathrm{F}$-value $=5.0 ; \mathrm{p}=0.0253)$, medical comorbidity (F-value $=5.6 ; \mathrm{p}=0.0180)$, and patients' severity as measured by the CGI-S scale (F-value $=33.6$; $\mathrm{p}<0.0001)$.

\section{Underproductive days related to the presence of PPS}

Analysis of underproductive days per week showed that patients with PPS in all the groups experienced a significantly higher number of underproductive days compared to patients without PPS (F-value $=6.1$ for the combination of diagnoses and pain $\mathrm{p}<0.0001, \mathrm{p}=0.0016, \mathrm{p}=0.0005$; $\mathrm{PPS}^{+}$vs. PPS for GAD+MDD+, GAD+MDD-, and control groups, respectively) (Figure 3 ). The presence of PPS in GAD+MDD+ patients was associated with a nearly twofold increase in the number of underproductive days $\left(\mathrm{LSM}[\mathrm{SD}]=3.5[0.2]\right.$ vs. $1.9[0.3] ; \mathrm{p}<0.0001, \mathrm{PPS}^{+}$vs. $\mathrm{PPS}^{-}$). Interestingly, in the absence of PPS, no statistically significant differences between study groups (GAD+MDD + , GAD+MDD-, control) were found regarding the number of underproductive days. Finally, other factors found to be related to more underproductive days were patients' severity measured by CGI-S scale (F-value $=12.4 ; \mathrm{p}<$ 0.0001 ) and the interaction between age and diagnosis $(\mathrm{F}$-value $=3.4 ; \mathrm{p}=0.0049)$. This means that the effect of diagnosis on the number of unproductive days varies according to age. Gender, medical comorbidity, and psychiatric comorbidity were not found to be significantly associated with underproductive days.

\section{Quality of life related to the presence of PPS}

The quality of life as assessed by the EQ-5D score showed that patients with PPS in all studied groups (viz. GAD with comorbid MDD, GAD without MDD, and control groups) experienced a significantly decreased quality of life as compared to patients without PPS (F-value $=30.3$ for the combination of diagnoses and pain, $\mathrm{p}<0.0001$; $\mathrm{PPS}^{+}$ vs. $\mathrm{PPS}^{-}$for $\mathrm{GAD}+\mathrm{MDD}+, \mathrm{GAD}+\mathrm{MDD}-$, and control 


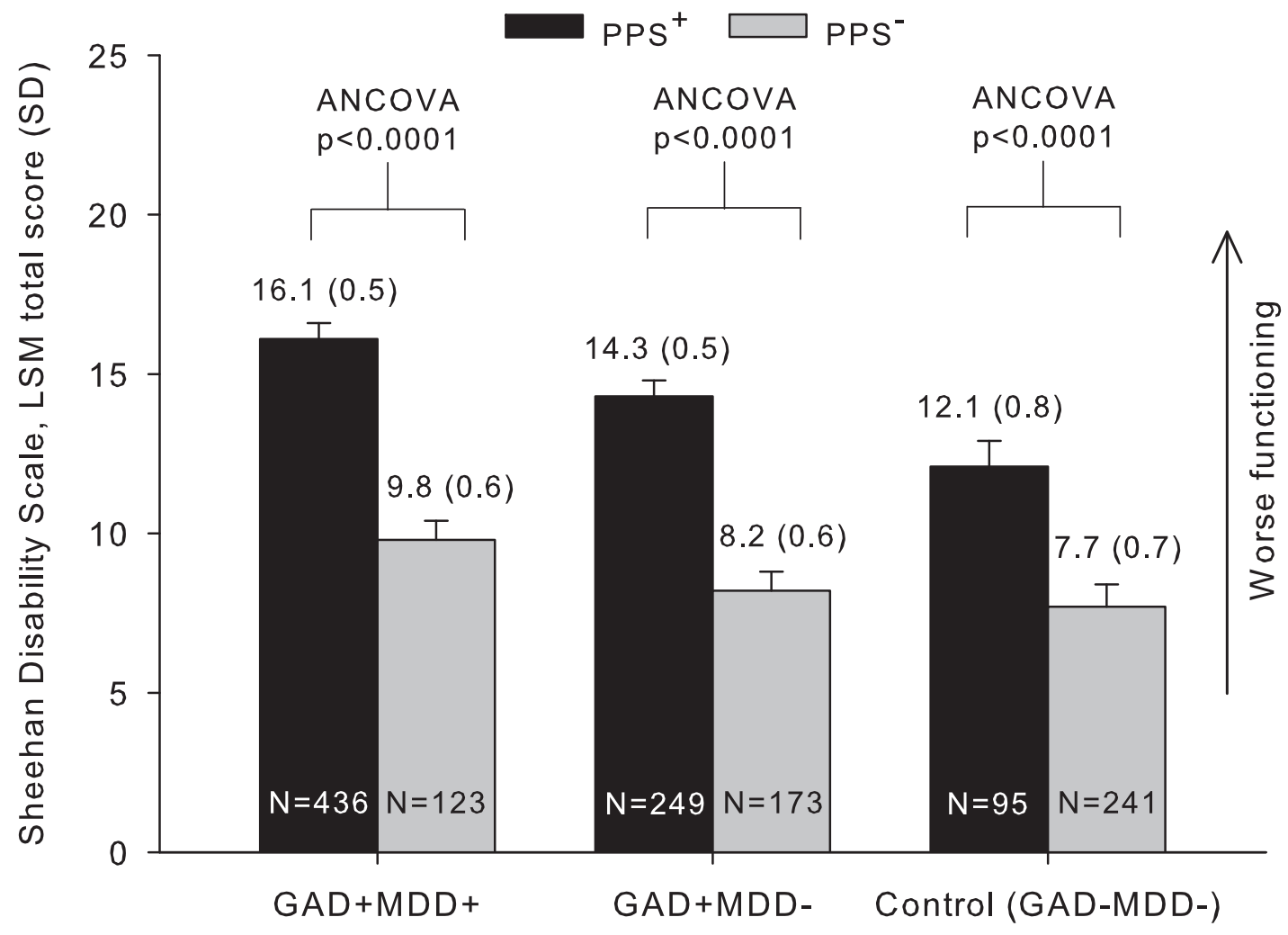

Figure 2 Functioning (SDS total score) by the presence of PPS in patients with GAD, with or without co-morbid MDD. Abbreviations: $\mathrm{GAD}=$ Generalized anxiety disorder; MDD = Major depressive disorder; PPS = Painful physical symptoms; SDS = Sheehan Disability Scale, SD = Standard deviation; LSM = Least square mean.

groups) (Figure 4). Similarly to functionality, the poorest quality of life was found in PPS positive GAD patients with comorbid MDD (LSM [SD] = 0.3 [0.0], p < 0.0001 vs. GAD+MDD- and control groups, with or without PPS). Results suggest that the presence of PPS alone contributes to additional decrease in quality of life. Other factors found to be significantly related to a lower quality of life were age $(\mathrm{F}$-value $=8.1 ; \mathrm{p}=0.0044)$, medical comorbidity $(\mathrm{F}$-value $=6.0 ; \mathrm{p}=0.0147)$, and patients' severity assessed by the CGI-S scale $(\mathrm{F}$-value $=44.3 ; \mathrm{p}<0.0001)$. Gender and psychiatric comorbidity were not significantly related $(\mathrm{p}=0.1925$ and $\mathrm{p}=0.6363$, respectively).

\section{Discussion}

This epidemiological study shows that PPS are a common feature in patients suffering from GAD, especially in those presenting comorbid MDD [8]. In this post hoc analysis, the presence of PPS was clinically and statistically significantly related to worse patients' functioning, productivity, and quality of life regardless of the patient's disease severity, age, gender, or comorbidity. The magnitude of this association between the presence of PPS and functioning impairment has proven to be relevant and persists even in the absence of comorbid MDD. Thus, the presence of PPS in patients with GAD, with or without comorbid MDD, was shown to be strongly associated with functional impairment in patient's work, social, and family lives. Hence, it is highly relevant for the physician to assess patients for PPS when evaluating for and treating GAD, regardless of the presence of comorbid MDD. A comprehensive evaluation of the role of these symptoms in a patient's ability to perform daily activities could improve the management of GAD and ultimately the patient's outcome.

The present study is the first to report the results of an assessment of functional impairment related to the presence of PPS in a large sample of primary care patients with GAD. The few similar published studies to date were either focused on community samples [33] or included patients suffering from any anxiety disorder other than GAD [34]. Our results are consistent with these previous studies, in which pain symptoms were 


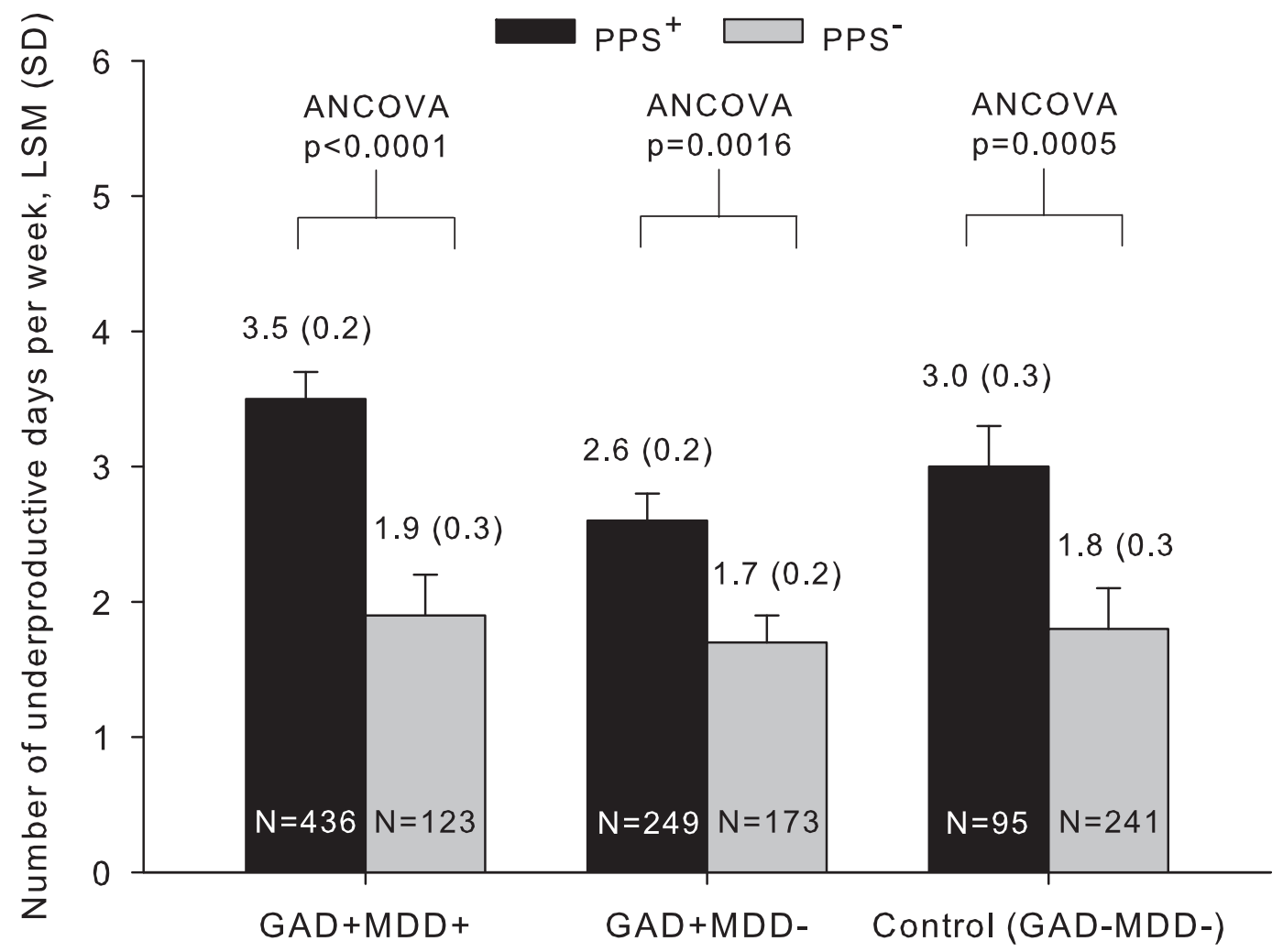

Figure 3 Underproductive days/weeks by the presence of PPS in patients with GAD, with or without comorbid MDD. Abbreviations: $\mathrm{GAD}=$ Generalized anxiety disorder; MDD = Major depressive disorder; PPS = Painful physical symptoms, SD = Standard deviation; LSM = Least square mean; ANCOVA = Analysis of covariance.

reported to be associated with poorer functioning in patients suffering from social anxiety and post-traumatic stress disorder [35] as well as in a community sample diagnosed with any anxiety disorder [33,34]. However, contrary to the results of Means-Christensen et al. [35], our study shows a clear association between PPS and a diagnosis of anxiety disorder (GAD in our study) that is not mediated by the presence of comorbid MDD. This could be due to the differences in patient samples and designs of both studies.

It is known that GAD is associated with clinically significant impairments in social, occupational, and/or family functioning [1]. As reported previously [1,2,36,37], several factors that contribute to greater functional impairment were determined, including the presence of psychiatric or medical comorbidity, age, patients' disease severity, and being female. However, none of the available studies on GAD focused on the effects of PPS on functional impairment. The current study contributes to the understanding of the specific role of such pain symptoms in worsening the functioning in patients with GAD. The presence of PPS is associated with a statistically and clinically significant impairment in patients' functioning, productivity, and quality of life, regardless of patients' disease severity, age, gender, or MDD comorbidity. In regard to productivity, patients with PPS had substantially more underproductive days per week compared to those without PPS. As expected, the presence of comorbid MDD was associated with worse productivity [38].

Several clinical implications could arise from these study results; PPS are frequent and significantly interfere with patients' family, social, and work activities. In order to ensure effective management of patients with GAD, it would be desirable to pay special attention not only to the typical symptoms of the disease but also to these PPS. Therefore, clinicians may routinely evaluate the extent to which symptoms impact patients' ability to perform well in a range of activities or areas. However, this task may not be as easy as it appears, given that functioning and pain symptoms are not commonly or systematically measured during the management of the disease. Also, primary care physicians do not always make the 


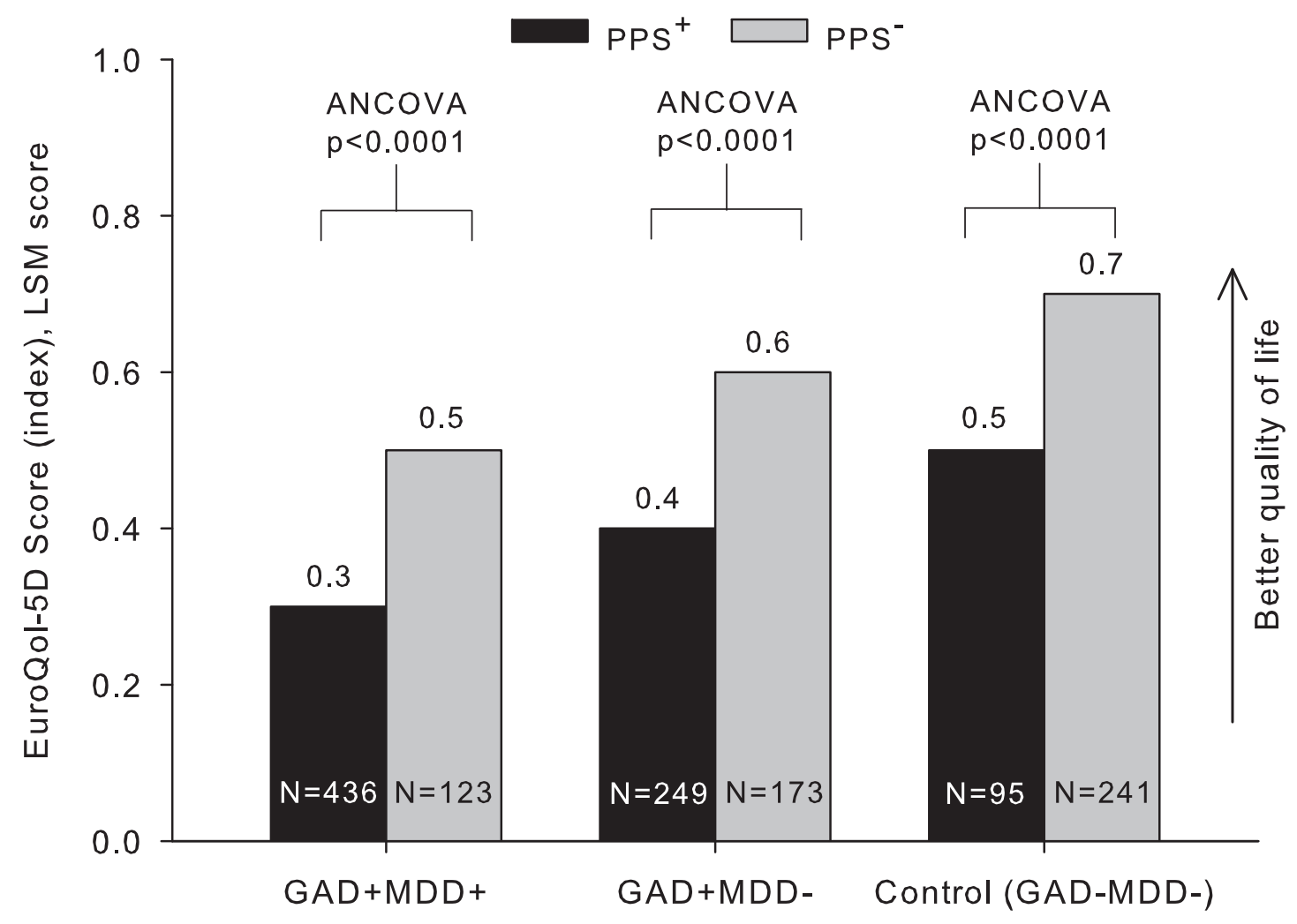

Figure 4 Quality of life (EuroQoL-5D total score) by the presence of PPS in patients with GAD, with or without comorbid MDD. Abbreviations: GAD = Generalized anxiety disorder; $\mathrm{MDD}=$ Major depressive disorder; PPS = Painful physical symptoms; $\mathrm{SD}=\mathrm{Standard}$ deviation.

association between pain symptoms and mental disorders; that is, they tend to associate pain symptoms more with a somatic disease rather than a mental disorder [31]. Primary care physicians may have to bear in mind that PPS are very commonly associated with both depression [39-43] and anxiety [8,32-34]. Moreover, they should be aware that that their presence could be associated with poorer treatment outcome and be a barrier to an adequate diagnosis of the disease $[42,44,45]$.

In accordance with current knowledge, this study found that GAD was not recognized by the physician for a large proportion of primary care patients, thus a large percentage of patients did not receive appropriate treatment for the disease [46]. Among the treatment options, only one-third of patients (or even fewer) was receiving antidepressant treatment, while benzodiazepines were being used predominantly. Awareness or recognition and adequate treatment of GAD would be important, particularly in primary care settings. The fact that patients with emotional distress report physical or somatic symptoms more often than psychological symptoms [47] could be a contributing factor for the under-recognition rates found in this study [8]. In order to improve the recognition of GAD in primary care, physicians should see these somatic symptoms as a high-risk factor not only for depression, but also for anxiety, especially if the symptoms are multiple and medically unexplained [42].

In the light of the study findings, primary care physicians should seek for an effective management of these PPS, and closely monitor the patients' improvement, so in this way the chances of functional recovery would be increased.

The present analysis has several limitations; the main limitation is that the analysis is focused mainly on correlations and associations, but does not provide any causal relationships. The results of the analysis cannot rule out possibility of patients' recall bias associated with the condition of underproductive days. However, the presence of a control group mitigates that bias. It could be argued that the use of categorical research-based criteria, such as the DSM-IV, is not useful in clinical practice because it artificially separates depression from anxiety. However, their use in this study is recommended in order to fully understand the specific role of pain symptoms in anxiety 
that is not mediated by the presence of MDD. Moreover, using standard criteria may allow further comparison with other research. The results should be not generalized to patients treated by psychiatrists, inpatients or other populations. Controls were selected based on the HADS-A subscale and total score on the HADS, and no structured interview was carried out. However, negative predictive values for selected cutoff points are 92\% (HADS-A) and 78\% (HADS) [48]. The major strength of this analysis is that it is the first time the specific role of PPS in functional impairment and their influence on underproductivity and quality of life was analyzed in a large sample of primary care patients with GAD, with or without MDD, by means of a controlled-design study. The naturalistic study design and the representativeness of the sample allow the generalization of the results to primary care patients with GAD. The presence of a control group of patients without MDD or GAD allows a more conclusive and comprehensive interpretation of the results.

\section{Conclusions}

The results of this study demonstrate a significant association of functional impairment with the presence of PPS in GAD patients, with or without comorbid MDD. Furthermore, the patients with PPS showed poorer quality of life. The frequent occurrence of PPS and their impact on patients' daily activities suggests that there is a need for accurate clinical diagnosis and management of PPS while evaluating and treating patients with GAD.

\section{Acknowledgements}

This study was supported by Eli Lilly and Company, Spain. The authors thank all the primary care centers and all the patients who participated in this study (F1J-XM-B024).

\section{Author details}

${ }^{1}$ Clinical Research Department, Lilly, SA, Avenida de la Industria, 30, 28108 Alcobendas, Spain. ${ }^{2}$ Hospital Universitario de Salamanca. School of Medicine, University of Salamanca, 37007 Salamanca, Spain. ${ }^{3}$ Primary Care Research Department, 6th Health Area, Servicio Madrileño de Salud, 28020 Madrid, Spain. ${ }^{4}$ Psychiatry Department, Hospital Puerta de Hierro, 28222 Madrid, Spain. ${ }^{5}$ Primary Care Department, Centro de Salud de la Ería, 33013 Oviedo, Spain. ${ }^{6}$ Consultant Scientific Communications and Training Lead, MCH - 92, Drop Code - 6122 Eli Lilly and Company, Lilly Corporate Center, Indianapolis, IN 46285, USA.

\section{Authors' contributions}

$I R, A L M, F C, L C, J A, P P$ and IG, have been involved in the study design, interpretation of the data, revision of the manuscript and the decision to submit the manuscript for publication. IR and DD have been involved in interpretation of the data and writing the manuscript. All authors have been involved in the decision to submit the manuscript for publication and have read and approved the final manuscript.

\section{Competing interests}

Drs. Romera, Gilaberte, Ms Polavieja are full time employees of Lilly SA. Dr. Desaiah was a full time employee of Eli Lilly and Company, Indianapolis, IN, USA during the conduct of the study. Dr. Arbesú has received grant support from Lilly SA; and has served as a consultant for and/or on advisory boards for Lilly SA; and has served as a speaker for Lilly SA, Lundbeck, Wyeth, Esteve, Almirall, Pfizer, Mylan and GSK. Dr. Montejo has received grant support from Eli Lilly, BMS-Otsuka, Lundbeck, Pfizer, AstraZeneca, Sanofi and GSK; has received honoraria from Servier, Eli Lilly, BMS-Otsuka. GSK, Sanofi, AstraZeneca, Boehriger and Wyeth; has served as a consultant for and/or on advisory boards for Eli Lilly, Bl, GlaxoSmithKline, Servier and AstraZeneca.

Received: 17 January 2011 Accepted: 21 April 2011

Published: 21 April 2011

\section{References}

1. Wittchen HU: Generalized anxiety disorder: prevalence, burden, and cost to society. Depress Anxiety 2002, 16:162-171.

2. Kroenke K, Spitzer RL, Williams JB, Monahan PO, Löwe B: Anxiety disorders in primary care: prevalence, impairment, comorbidity, and detection. Ann Intern Med 2007, 146:317-325.

3. Mendlowicz MV, Stein MB: Quality of life in individuals with anxiety disorders. Am J Psychiatry 2000, 157:669-682.

4. Cramer V, Torgersen S, Kringlen E: Quality of life and anxiety disorders: a population study. J Nerv Ment Dis 2005, 193:196-202.

5. Beard C, Weisberg RB, Keller MB: Health-related Quality of Life across the anxiety disorders: findings from a sample of primary care patients. J Anxiety Disord 2010, 24:559-564.

6. Schonfeld WH, Verboncoeur CJ, Fifer SK, Lipschutz RC, Lubeck DP, Buesching DP: The functioning and well-being of patients with unrecognized anxiety disorders and major depressive disorder. J Affect Disord 1997, 43:105-119.

7. Marciniak M, Lage MJ, Landbloom RP, Dunayevich E, Bowman L: Medical and productivity costs of anxiety disorders: case control study. Depress Anxiety 2004, 19:112-120.

8. Romera I, Fernández-Pérez S, Montejo AL, Caballero F, Caballero L, Arbesú JÁ, Delgado-Cohen H, Desaiah D, Polavieja P, Gilaberte I: Generalized anxiety disorder, with or without co-morbid major depressive disorder, in primary care: prevalence of painful somatic symptoms, functioning and health status. J Affect Disord 2010, 127:160-168.

9. Kubarych TS, Aggen SH, Hettema JM, Kendler KS, Neale MC: Endorsement frequencies and factor structure of DSM-III-R and DSM-IV Generalized Anxiety Disorder symptoms in women: implications for future research, classification, clinical practice and comorbidity. Int J Methods Psychiatr Res 2005, 14:69-81.

10. Joormann J, Stöber J: Somatic symptoms of generalized anxiety disorder from the DSM-IV: associations with pathological worry and depression symptoms in a nonclinical sample. J Anxiety Disord 1999, 13:491-503.

11. Brown TA: The nature of generalized anxiety disorder and pathological worry: current evidence and conceptual models. Can J Psychiatry 1997, 42:817-825.

12. Marten PA, Brown TA, Barlow DH, Borkovec TD, Shear MK, Lydiard RB: Evaluation of the ratings comprising the associated symptom criterion of DSM-III-R generalized anxiety disorder. J Nerv Ment Dis 1993, 181:676-682.

13. American Psychiatric Association: Diagnostic and Statistical Manual of Mental Disorders. Fourth edition. Washington, DC: American Psychiatric Press; 1994.

14. Aldao A, Mennin DS, Linardatos E, Fresco DM: Differential patterns of physical symptoms and subjective processes in generalized anxiety disorder and unipolar depression. J Anxiety Disord 2010, 24:250-259.

15. Beesdo K, Jacobi F, Hoyer J, Low NC, Höfler M, Wittchen HU: Pain associated with specific anxiety and depressive disorders in a nationally representative population sample. Soc Psychiatry Psychiatr Epidemiol 2010, 45:89-104

16. Yonkers KA, Dyck IR, Warshaw M, Keller MB: Factors predicting the clinical course of generalised anxiety disorder. Br J Psychiatry 2000 176:544-549.

17. Asmundson GJ, Katz J: Understanding the co-occurrence of anxiety disorders and chronic pain: state-of-the-art. Depress Anxiety 2009, 26:888-901.

18. Carleton RN, Abrams MP, Asmundson GJ, Antony MM, McCabe RE: Painrelated anxiety and anxiety sensitivity across anxiety and depressive disorders. J Anxiety Disord 2009, 23:791-798.

19. Bair MJ, Robinson RL, Katon W, Kroenke K: Depression and pain comorbidity: a literature review. Arch Intern Med 2003, 163:2433-2445. 
20. García-Campayo J, Ayuso-Mateos JL, Caballero L, Romera I, Aragonés E, Rodríguez-Artalejo F, Quail D, Gilaberte I: Relationship of Somatic Symptoms With Depression Severity, Quality of Life, and Health Resources Utilization in Patients With Major Depressive Disorder Seeking Primary Health Care in Spain. Prim Care Companion J Clin Psychiatry 2008, 10:355-362.

21. Muñoz RA, McBride ME, Brnabic AJ, López CJ, Hetem LA, Secin R, Dueñas HJ: Major depressive disorder in Latin America: the relationship between depression severity, painful somatic symptoms, and quality of life. J Affect Disord 2005, 86:93-98.

22. Reed C, Monz BU, Perahia DG, Gandhi P, Bauer M, Dantchev N, Demyttenaere K, Garcia-Cebrian A, Grassi L, Quail D, Tylee A, Montejo AL: Quality of life outcomes among patients with depression after 6 months of starting treatment: results from FINDER. J Affect Disord 2009, 113:296-302.

23. Zigmond AS, Snaith RP: The hospital anxiety and depression scale. Acta Psychiatr Scand 1983, 67:361-370.

24. Sheehan DV, Lecrubier $Y$, Sheehan $\mathrm{KH}$, Amorim $\mathrm{P}$, Janavs J, Weiller $\mathrm{E}$, Hergueta T, Baker R, Dunbar GC: The Mini-International Neuropsychiatric Interview (M.I.N.I.): the development and validation of a structured diagnostic psychiatric interview for DSM-IV and ICD-10. J Clin Psychiatry 1998, 59(Suppl 20):22-33.

25. DeLoach LJ, Higgins MS, Caplan AB, Stiff JL: The visual analog scale in the immediate postoperative period: intrasubject variability and correlation with a numeric scale. Anesth Analg 1998, 86:102-106.

26. Weisberg RB, Bruce SE, Machan JT, Kessler RC, Culpepper L, Keller MB: Nonpsychiatric illness among primary care patients with trauma histories and posttraumatic stress disorder. Psychiatr Serv 2002, 53:848-854.

27. Leon AC, Olfson M, Portera L, Farber L, Sheehan DV: Assessing psychiatric impairment in primary care with the Sheehan Disability Scale. Int J Psychiatry Med 1997, 27:93-105.

28. Kind P: The EuroQol Instrument: an index of health related quality of life. Edited by: Spilker B. Philadelphia, PA: Lippincot-Raven; , Second 1996:191-201.

29. Guy G: Clinical global impression. Book Clinical global impression (Editor ed. ^eds.) City: National Institute for Mental Health; 1976.

30. Russell JM, Weisberg R, Fava M, Hartford JT, Erickson JS, D'Souza DN: Efficacy of duloxetine in the treatment of generalized anxiety disorder in patients with clinically significant pain symptoms. Depress Anxiety 2008, 25:E1-11.

31. Demyttenaere K, Bonnewyn A, Bruffaerts R, Brugha T, De Graaf R, Alonso J: Comorbid painful physical symptoms and depression: prevalence, work loss, and help seeking. J Affect Disord 2006, 92:185-193.

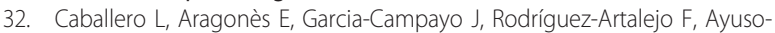
Mateos JL, Polavieja P, Gómez-Utrero E, Romera I, Gilaberte I: Prevalence, characteristics, and attribution of somatic symptoms in Spanish patients with major depressive disorder seeking primary health care. Psychosomatics 2008, 49:520-529.

33. Beesdo K, Hoyer J, Jacobi F, Low NC, Höfler M, Wittchen HU: Association between generalized anxiety levels and pain in a community sample: evidence for diagnostic specificity. J Anxiety Disord 2009, 23:684-693.

34. Beesdo K, Knappe S, Pine DS: Anxiety and anxiety disorders in children and adolescents: developmental issues and implications for DSM-V. Psychiatr Clin North Am 2009, 32:483-524.

35. Means-Christensen AJ, Roy-Byrne PP, Sherbourne CD, Craske MG, Stein MB: Relationships among pain, anxiety, and depression in primary care. Depress Anxiety 2008, 25:593-600.

36. Ansseau M, Fischler B, Dierick M, Mignon A, Leyman S: Prevalence and impact of generalized anxiety disorder and major depression in primary care in Belgium and Luxemburg: the GADIS study. Eur Psychiatry 2005, 20:229-235.

37. Kessler RC, Brandenburg N, Lane M, Roy-Byrne P, Stang PD, Stein DJ, Wittchen HU: Rethinking the duration requirement for generalized anxiety disorder: evidence from the National Comorbidity Survey Replication. Psychol Med 2005, 35:1073-1082.

38. Weiller E, Bisserbe JC, Maier W, Lecrubier Y: Prevalence and recognition of anxiety syndromes in five European primary care settings. A report from the WHO study on Psychological Problems in General Health Care. $\mathrm{Br} J$ Psychiatry Supp/ 1998, 18-23.
39. Bao Y, Sturm R, Croghan TW: A national study of the effect of chronic pain on the use of health care by depressed persons. Psychiatr Serv 2003, 54:693-697.

40. McWilliams LA, Goodwin RD, Cox BJ: Depression and anxiety associated with three pain conditions: results from a nationally representative sample. Pain 2004, 111:77-83.

41. Lee P, Zhang M, Hong JP, Chua HC, Chen KP, Tang SW, Chan BT, Lee MS, Lee B, Gallagher GL, Dossenbach M: Frequency of painful physical symptoms with major depressive disorder in asia: relationship with disease severity and quality of life. J Clin Psychiatry 2009, 70:83-91.

42. Agüera L, Failde I, Cervilla JA, Díaz-Fernández P, Mico JA: Medically unexplained pain complaints are associated with underlying unrecognized mood disorders in primary care. BMC Fam Pract 2010, 11:17.

43. Agüera-Ortiz L, Failde I, Mico JA, Cervilla J, López-lbor JJ: Pain as a symptom of depression: Prevalence and clinical correlates in patients attending psychiatric clinics. J Affect Disord 2011, 130:106-112.

44. Leuchter AF, Husain MM, Cook IA, Trivedi MH, Wisniewski SR, Gilmer WS, Luther JF, Fava M, Rush AJ: Painful physical symptoms and treatment outcome in major depressive disorder: a STAR*D (Sequenced Treatment Alternatives to Relieve Depression) report. Psychol Med 2010, 40:239-251.

45. Bair MJ, Robinson RL, Eckert GJ, Stang PE, Croghan TW, Kroenke K: Impact of pain on depression treatment response in primary care. Psychosom Med 2004, 66:17-22.

46. Wang PS, Lane M, Olfson M, Pincus HA, Wells KB, Kessler RC: Twelve-month use of mental health services in the United States: results from the National Comorbidity Survey Replication. Arch Gen Psychiatry 2005 62:629-640.

47. Kirmayer $\amalg$, Robbins $J M$, Dworkind M, Yaffe MJ: Somatization and the recognition of depression and anxiety in primary care. Am J Psychiatry 1993, 150:734-741.

48. Herrero MJ, Blanch J, Peri JM, De Pablo J, Pintor L, Bulbena A: A validation study of the hospital anxiety and depression scale (HADS) in a Spanish population. Gen Hosp Psychiatry 2003, 25:277-283.

\section{Pre-publication history}

The pre-publication history for this paper can be accessed here: http://www.biomedcentral.com/1471-244X/11/69/prepub

\section{doi:10.1186/1471-244X-11-69}

Cite this article as: Romera et al.: Functional impairment related to painful physical symptoms in patients with generalized anxiety disorder with or without comorbid major depressive disorder: post hoc analysis of a cross-sectional study. BMC Psychiatry 2011 11:69.

\section{Submit your next manuscript to BioMed Central and take full advantage of:}

- Convenient online submission

- Thorough peer review

- No space constraints or color figure charges

- Immediate publication on acceptance

- Inclusion in PubMed, CAS, Scopus and Google Scholar

- Research which is freely available for redistribution

Submit your manuscript at www.biomedcentral.com/submit
C Biomed Central 